Mojena Wilce, Y., y Salcines-Talledo, I. (septiembre-diciembre, 2021). Percepciones de los estudiantes de Educación Secundaria sobre el valor educativo de los videojuegos y su diseño como estrategia pedagógica. Revista Virtual Universidad Católica del Norte, (64), 5-40.

\title{
Percepciones de los estudiantes de Educación Secundaria sobre el valor educativo de los videojuegos y su diseño como estrategia pedagógica
}

Students' perceptions of the educational value of videogames and their design as a pedagogical strategy

Yolanda Mojena Wilce

Máster en Formación del Profesorado de Secundaria

Facultad de Educación, Universidad de Cantabria

Santander, España

yomowilce@gmail.com

Orcid: https://orcid.org/0000-0003-0404-3756

Irina Salcines-Talledo

Doctora en Educación

Facultad de Educación, Universidad de Cantabria

Santander, España

salcinesi@unican.es

Orcid: https://orcid.org/0000-0003-0170-9807

Recibido: 03 de julio de 2020

Evaluado: 19 de enero de 2021

Aprobado: 06 de abril de 2021

Tipo de artículo: Investigación Científica y Tecnológica

\section{Resumen}

Los videojuegos se han situado como una de las principales industrias del ocio y entretenimiento en España, pero también ha habido un incremento significativo en su uso con fines educativos. Estos se utilizan como un elemento de motivación en el aula, que ha demostrado tener múltiples beneficios sobre el aprendizaje y el desarrollo de habilidades cognitivas. En este trabajo, a través 
de una investigación cuantitativa, no experimental y descriptiva, se profundizó en el valor educativo del videojuego y en su diseño como estrategia pedagógica. Para ello, se recogieron las percepciones del alumnado de secundaria, mediante un cuestionario ad hoc en el que participaron 55 sujetos. Los principales resultados señalan el amplio interés de los estudiantes por el aprendizaje, a través de videojuegos.

Palabras clave: Aprendizaje cooperativo; Diseño de Videojuegos; Educación Secundaria; Gamificación; Videojuegos.

\begin{abstract}
Videogames have become one of the main industries of leisure and entertainment in Spain, but there has also been a significant increase in the use of videogames for educational purposes. These are used in the classroom as a motivational tool, which has been proven to have multiple benefits over students' learning and developing cognitive skills. In this work the educational value of videogames and its design as a pedagogical strategy are explored, through a quantitative, nonexperimental and descriptive research. For that purpose, the perceptions of secondary school students are gathered through an ad hoc questionnaire in which 55 participants took part. The major findings point out a wide interest from the students towards learning through videogames.
\end{abstract}

Keywords: Cooperative Learning; Game Design; Education; Gamification; Videogames.

\title{
Introducción
}

El auge de las nuevas tecnologías ha tenido un gran impacto sobre todos los ámbitos de la sociedad, incluyendo el educativo. El desarrollo de las tecnologías de la información y la comunicación -TIC- ha cambiado la forma de relacionarse de los adolescentes, así como su tiempo de ocio y su percepción sobre el aprendizaje. Los centros de Educación Secundaria en España presentan nuevos retos para abarcar, entre ellos la falta de motivación del alumnado, adaptar el currículum a la diversidad de los estudiantes y un estancamiento en los resultados académicos a 
nivel europeo. Según el informe PISA (OCDE, 2018), concretamente los alumnos españoles están por debajo de la media europea en ciencias y matemáticas.

Por otro lado, existe una creciente necesidad de un cambio educativo hacia la escuela inclusiva, a través de los nuevos medios (Bernaschina Cuadra, 2019) y de utilizar metodologías innovadoras que otorguen oportunidades de interacción y cooperación en el aprendizaje (García González, 2015). Tal y como afirman Calvo González y San Fabián (2018), "las tecnologías son elementos clave de los procesos formativos escolares" (p. 6). Con la llegada del Programa Escuela 2.0, los centros educativos fueron dotados de pizarras digitales, aulas de informática y ordenadores personales. Aunque las herramientas no proporcionan un cambio metodológico, el uso de estos recursos ha supuesto que el profesorado se replantee sus prácticas de aula, fomentado un aprendizaje basado en la autonomía y la colaboración (González y Martín, 2019).

En relación con este proceso de integración digital, datos recientes del Ministerio de Educación y Formación Profesional (2020) revelan que, en el curso 2018/2019, ya existía una ratio de 2.9 alumnos por dispositivo y un $76.4 \%$ de centros contaba con una conexión a internet de más de $20 \mathrm{MB}$ de ancho de banda. Esta introducción de tecnología a las aulas ha permitido diversificar los modelos educativos y las estrategias pedagógicas, destacando entre ellas la educación basada en juegos (Giraldo Plaza y Mateus, 2010) y otras metodologías basadas en TIC para el desarrollo de proyectos innovadores en las aulas (Pardo Baldoví, 2019), como la clase invertida (Akçayır \& Akçayır, 2018), la gamificación (Suárez-Álvarez y Vázquez-Barrio, 2019) o el uso de la realidad aumentada (De la Horra Villacé, 2016).

Concretamente, conforme a las experiencias relacionadas con videojuegos, existen una serie de factores sociales y tecnológicos que han contribuido al crecimiento de estas, destacando la aparición de herramientas y programas educativos que hacen del desarrollo de videojuegos una práctica más accesible, una mayor diversidad en la audiencia del medio, y la expansión del smartphone y, con ello, de los videojuegos para móviles, que permiten jugar en cualquier lugar y con jugadores de todas partes del mundo (Kapp, 2013).

Por tanto, este trabajo pretende estudiar concretamente el valor educativo del videojuego en las aulas de Educación Secundaria y el potencial de nuevas estrategias pedagógicas basadas en los videojuegos. Para ello, se realiza en primer lugar una revisión teórica, contextualizando la temática y abordando las principales ventajas y limitaciones de los videojuegos educativos. A 
Percepciones de

los estudiantes
Percepciones de los estudiantes | Revista Virtual

Universidad Católica del Norte, 64, 5-40

ISSN: 0124-5821 (En línea)

continuación, se analizan los principales ejemplos de videojuegos comerciales con aplicaciones en el aula y el diseño de videojuegos como estrategia pedagógica. Por último, se presenta una investigación enfocada a las percepciones de los alumnos sobre el uso pedagógico de los videojuegos.

\section{Marco teórico}

\section{Los videojuegos como fenómeno social y educativo}

En los últimos años, el videojuego se ha establecido como un elemento facilitador del aprendizaje (Sánchez Peris y Esnaola Horacek, 2014), que potencia la atención y el interés educativo entre los usuarios de nuevas tecnologías. Además de la motivación, varios estudios han analizado la repercusión del uso de juegos sobre las capacidades sensoriales e intelectuales (López Raventós, 2016; Núñez-Barriopedro et al., 2020) y su utilidad para enseñar conceptos complejos, mediante la conversión de tareas difíciles y tediosas en tareas divertidas que formen parte de una buena historia (Holguin et al., 2020; Padilla Zea, 2011).

Según Wijman (2019), en su Informe Global, el mercado de los videojuegos ha aumentado un $9.6 \%$ desde 2018, sumando un total de 151.1 billones de dólares facturados en este último año. Actualmente hay una población mundial de 2.5 billones de jugadores, destacando los usuarios de consola y juegos móvil. En el ámbito nacional, datos de la Asociación Española de Videojuegos AEVI- (2019) indican que los videojuegos siguen siendo la primera opción de ocio audiovisual y cultural en España, habiendo facturado un total de 147.9 millones de euros en este último año, y con una población de jugadores de 15 millones.

Los adolescentes se encuentran entre los grupos de edad que más juegan a videojuegos en España, situándose un $68 \%$ de los jugadores entre los 11 y 14 años, y un $66 \%$ entre los 15 y los 24 (AEVI, 2019). Considerando las nuevas generaciones de nativos digitales, el uso de videojuegos en las aulas parece un paso adelante hacia nuevas formas de aprendizaje (Prensky, 2011). En respuesta a esto, ha comenzado a aumentar el interés de muchos docentes por el desarrollo de videojuegos que permitan una mayor adaptación a las necesidades del aula. No obstante, la implementación de un videojuego requiere unos conocimientos avanzados de 
programación, animación, sonido, mecánicas de juego, entre otros, y las conclusiones del trabajo realizado por Dorado Gómez y Gewec Barujel (2017) revelan una falta de formación del profesorado para la elaboración de sus propios materiales docentes.

El diseño de videojuegos es una tarea que implica conocimiento sobre múltiples áreas bien diferenciadas, pero intrínsecamente relacionadas entre sí (Garmen et al., 2019). Nallar (2016), defiende la necesidad de definir "un conjunto de reglas, condiciones de victoria y derrota, dinámica, interacción, meta de diseño, objetivos y desafíos, aprendizaje, sociabilidad y expresión, todo ello en un conjunto indisoluble de narrativa ficcional y su ambiente, programación, estética gráfica y sonido" (p. 1).

Esta necesidad de coordinación entre varias disciplinas y dominio de la materia sitúa el diseño de videojuegos como una tarea que favorece el aprendizaje individual y las habilidades sociales. El aprendizaje colaborativo soportado por computador (CSCL) ya es un área ampliamente estudiada (Jeong et al., 2019), pero en los últimos años ha aparecido también el concepto de aprendizaje colaborativo soportado por videojuegos (VGSCL). Este último, permite la implementación de un modelo basado en involucrar al profesor en el proceso de diseño, enlazar elementos propios del videojuego con los contenidos educativos y monitorizar el aprendizaje de los alumnos y su interacción (Padilla Zea et al., 2012).

\section{Ventajas y limitaciones de los videojuegos}

El interés por los videojuegos educativos ha incrementado en gran medida por el papel que juegan en el proceso de aprendizaje, su capacidad para captar la atención de los alumnos y su incremento de la motivación, tanto individual como en el aula. Según Barbosa et al. (2014), este tipo de juegos, definidos en muchas ocasiones como juegos serios por su propósito más allá del entretenimiento, han sido utilizados en muchos otros sectores como el militar, empresarial y sanidad. También, en el ámbito periodístico se observan ejemplos de videojuegos inspirados por situaciones y problemáticas del mundo real (Tejedor y Tusa Jumbo, 2020).

Hay diversos estudios que han investigado los efectos de los videojuegos, así como sus beneficios como herramienta educativa. Prensky (2011) ya adelantaba que los videojuegos permiten la adquisición de atributos y técnicas que asisten a la comprensión de conceptos 
complejos, y la propia AEVI (2019) condujo un estudio, a nivel global, donde reivindicaba los valores del videojuego y promovía el consumo responsable al conjunto de la sociedad. En este, se concluyó que los videojuegos mejoran la memoria y las habilidades cognitivas, enriquecen la capacidad de lógica, deducción y orientación espacial, y son útiles de cara a acelerar el proceso de adquisición de contenidos.

Asimismo, los docentes también consideran que favorecen el desarrollo de habilidades cognitivas, psicomotoras, habilidades personales y sociales, y son un medio para la transmisión de valores (Conde-Cortabitarte et al., 2020; López Gómez y Rodríguez Rodríguez, 2016). Cabe destacar también la revisión realizada por Yepes Miranda (2020), la cual describe el enfoque STEM y cómo este "fortalece los procesos de enseñanza-aprendizaje en las instituciones educativas" (p. 9).

Un estudio realizado por Rivera Arteaga y Torres Cosío (2018), hace una revisión de la literatura sobre los videojuegos y el desarrollo de habilidades del pensamiento. En dicho trabajo, se destacan específicamente el desarrollo del pensamiento lógico y la capacidad de resolución de problemas, la alfabetización digital, la creatividad y las habilidades de socialización. Además, sus autores afirman:

Los videojuegos generan aprendizaje significativo, ya que aprenden lo jugado porque lo viven dentro de la simulación del videojuego, tomando en cuenta que los videojuegos son una representación de la realidad con variantes de ficción, pero, a fin de cuentas, siempre parten de la realidad. (p. 16)

Del mismo modo, los videojuegos permiten que los alumnos interactúen con problemas reales sin ningún riesgo adicional, como podría ser en el caso de los simuladores de vuelo o juegos basados en finanzas. Esta simulación permite, además, una mayor inmersión, es decir, una mayor identificación entre el jugador y la parte de la realidad representada (López Raventós, 2016), y reforzar una toma de decisiones más consciente, pues cada acción tendrá unas consecuencias reales. Más allá de esto, la dificultad de los problemas planteados puede adaptarse al ritmo y nivel de habilidad del alumno.

Continuando con sus beneficios, y tal y como se puede observar en algunos de los principales ejemplos comerciales, como League of Legends o World of Warcraft, los videojuegos multijugador potencian además la creación de comunidades y lazos sociales entre jugadores 
(Depping \& Mandryk, 2017), que pueden implicar experiencias de aprendizaje significativo fuera de las aulas (Sánchez Guzmán y Galvis Martínez, 2016). Este tipo de experiencias, que rompen con el esquema de una educación limitada a las aulas, puede englobarse dentro del aprendizaje ubicuo, es decir, aquel que tiene lugar en cualquier lugar y momento, sin formar parte de una actividad diseñada para ello (Burbules, 2012). Según Quesada y Tejedor (2016), "se trata de tareas que los profesores enseñan en el aula, y que el videojuego enseña de forma informal a sus jugadores" (p. 10).

Por último, en relación con el ámbito de la sanidad, el trabajo de Del Corral Núñez-Flores (2018) estudia los efectos de los videojuegos en programas de rehabilitación en pacientes con fibrosis quística, obteniendo "incrementos en la tolerancia al esfuerzo, fuerza muscular y calidad de vida relacionada con la salud" (p. 22). Ledo Rubio et al. (2016), también profundizan en este ámbito, centrándose en los usos del videojuego en pacientes con trastorno por déficit de atención e hiperactividad (TDAH), trastorno del espectro del autismo (TEA), fobia social y otras indicaciones terapéuticas, como adicción, trastornos alimenticios, tratamiento del dolor, estimulación del ejercicio físico y la prevención, promoción y mejora de la salud.

Concretamente, en este trabajo se investigan las percepciones de los estudiantes de secundaria, respecto al impacto de los videojuegos en la motivación en el aula, el desarrollo de habilidades en el manejo de información y nuevas tecnologías, las capacidades de aprendizaje, comunicación, colaboración y resolución de problemas, y el desarrollo de habilidades profesionales y de la creatividad. Del mismo modo, se estudian las perspectivas sobre los videojuegos diseñados con propósitos educativos y su capacidad lúdica, de innovación, para el desarrollo de habilidades y conocimientos, y su atractivo.

Aunque el auge de los juegos serios también ha sido un factor determinante a la hora de potenciar sus usos pedagógicos y formativos, siguen existiendo una serie de prejuicios y alarma social entre las familias, respecto a los videojuegos (Navas y Postigo, 2020). Rubio Méndez (2012) afirma que otras barreras a la hora de incorporar estos sistemas son la "necesidad de llevar a cabo una alfabetización digital eficaz (...) y la asimetría existente entre diferentes grupos sociales" (p. 118). Las perspectivas de los docentes son variadas, pero cada vez son más los estudios que desmitifican el videojuego como algo perjudicial para los jóvenes (Soto-Ardila et al., 2019). 
Percepciones de

los estudiantes
Percepciones de los estudiantes | Revista Virtual

Universidad Católica del Norte, 64, 5-40

ISSN: 0124-5821 (En línea)

Más allá de los prejuicios sociales, hay una serie de riesgos ligados a un uso inadecuado de los videojuegos. El trabajo de Ponce Blandón et al. (2020) analiza si existe relación entre las experiencias de los adolescentes con videojuegos y situaciones de aislamiento en el núcleo familiar, concluyendo efectos negativos tan solo en caso de una sobreexposición temporal. En relación con esto, Marengo et al. (2015) estudian la posibilidad de desarrollar dependencia a los videojuegos en ciertos individuos, influenciados por su grado de emoción y gratificación. En individuos con predisposición, la adicción a los videojuegos comparte características con otras adicciones, como falta de atención, impulsividad y otros efectos psicosociales (Buiza-Aguado et al., 2017).

Respecto a la relación entre videojuegos violentos y agresividad, existe controversia sobre si estos generan o no este tipo de conductas. Un estudio realizado por la Universidad de Dartmouth concluye que jugar videojuegos violentos está asociado con mayores niveles de agresión física a lo largo del tiempo (Prescott et al., 2018). Además, utiliza un modelo basado en el origen étnico para valorar si la cultura influye en la respuesta a contenidos violentos y justificar las discrepancias encontradas en la literatura.

Por otro lado, García Cernaz (2017) no considera la agresividad como un efecto secundario de la exposición a videojuegos violentos. Contrariamente, defiende que "una elevada frecuencia de uso de videojuegos con contenidos violentos y de modo solitario, más que ser causante de 'trastornos', puede interpretarse como síntoma indicador de un padecimiento" (p. 161), e insiste en la necesidad de regulación adulta para un uso adecuado del medio y explotar sus beneficios. En línea con esta idea, Soriani et al. (2018) exploran la violencia en videojuegos como una oportunidad hacia el pensamiento crítico, siempre bajo la supervisión de un adulto responsable.

Otro factor para considerar es la tendencia al sedentarismo (Ramírez-Granizo et al., 2020), que puede darse al sustituir opciones de ocio, ligadas a la actividad física, con las nuevas tendencias de ocio interactivo, que implican altas horas de exposición a la pantalla. Corvos et al. (2020) explora los videojuegos activos como complemento a la actividad física diaria y oportunidad de ocio digital activo. Tanto el sedentarismo como otros factores de riesgo son evitables llevando a cabo un uso responsable de los videojuegos. En el caso de patologías físicas, como la epilepsia, los expertos recomiendan medidas preventivas como gafas de sol y evitar un uso prolongado de videojuegos (Ruiz Falcó, 2018). Las empresas de videojuegos advierten de los potenciales riesgos 
para estos individuos, en las pantallas de carga de sus juegos, informando de si estos contienen cambios muy agresivos de iluminación o patrones visuales.

\section{Los videojuegos en educación}

Con el objetivo de valorar la utilidad de los videojuegos en el entorno educativo, así como sus posibilidades para ser integrados en el currículum, en la tabla 1 se hace una revisión de los videojuegos comerciales que han tenido especial relevancia en educación durante los últimos años, entendiendo como videojuegos comerciales "aquellos que han sido diseñados para el ocio" (Lacasa et al., 2010, p. 11).

Se han escogido específicamente videojuegos de carácter comercial y directamente relacionados con ámbitos de conocimiento trabajados en el currículo de Educación Secundaria, considerando que los juegos enfocados a propósitos educativos suelen mostrar carencias en lo que se refiere al aspecto lúdico. Dorado Gómez y Gewec Barujel (2017) afirman que "los contenidos abordados por los videojuegos educativos son fundamentalmente académicos, con sesgos memorísticos y dejan de lado aspectos de gran relevancia como la libertad, la motivación, la toma de decisiones y el pensamiento crítico" (p. 184).

\section{Tabla 1}

Ejemplos de videojuegos comerciales con contenidos educativos

\begin{tabular}{ccccc}
\hline Videojuego & $\begin{array}{c}\text { Año } \\
\text { publicación }\end{array}$ & $\begin{array}{c}\text { Edad } \\
\text { objetivo }\end{array}$ & Géneros & Ámbito de conocimiento \\
\hline Gris & 2018 & $7+$ & $\begin{array}{c}\text { Plataforma } \\
\text { Aventuras }\end{array}$ & $\begin{array}{c}\text { Arte } \\
\text { Lengua y literatura }\end{array}$ \\
\hline Minecraft & 2011 & $3-14+$ & $\begin{array}{c}\text { Sandbox } \\
\text { Multijugador }\end{array}$ & $\begin{array}{c}\text { Planes adaptados a cada } \\
\text { asignatura }\end{array}$ \\
\hline Assassin's Creed & 2017 & $\begin{array}{c}18+ \\
\text { Control } \\
\text { parental }\end{array}$ & $\begin{array}{c}\text { Acción } \\
\text { Aventuras }\end{array}$ \\
\hline
\end{tabular}


Percepciones de

los estudiantes
Percepciones de los estudiantes | Revista Virtual

Universidad Católica del Norte, 64, 5-40

ISSN: 0124-5821 (En línea)

\begin{tabular}{|c|c|c|c|c|}
\hline Sim City & 2014 & $11-14+$ & $\begin{array}{l}\text { Simulación } \\
\text { Gestión de } \\
\text { ciudades }\end{array}$ & $\begin{array}{l}\text { Economía } \\
\text { Ciencia } \\
\text { Matemáticas }\end{array}$ \\
\hline Civilization & 2016 & $12+$ & $\begin{array}{l}\text { Estrategia por } \\
\text { turnos }\end{array}$ & $\begin{array}{l}\text { Relaciones entre desarrollo } \\
\text { político, económico, militar y } \\
\text { tecnológico }\end{array}$ \\
\hline Spore & 2008 & $12+$ & $\begin{array}{l}\text { Simulación } \\
\text { Estrategia } \\
\text { Modo Dios }\end{array}$ & $\begin{array}{l}\text { Biología } \\
\text { Evolución } \\
\text { Ecosistemas }\end{array}$ \\
\hline $\begin{array}{c}\text { Europa } \\
\text { Universalis }\end{array}$ & 2013 & $12+$ & Estrategia & $\begin{array}{c}\text { Historia } \\
\text { Geografía }\end{array}$ \\
\hline Scribblenauts & 2009 & $12+$ & $\begin{array}{l}\text { Puzzles } \\
\text { Modo Dios }\end{array}$ & $\begin{array}{c}\text { Lengua } \\
\text { Vocabulario }\end{array}$ \\
\hline $\begin{array}{c}\text { Kerbal Space } \\
\text { Program }\end{array}$ & 2015 & $5-18+$ & $\begin{array}{l}\text { Simulación } \\
\text { espacial }\end{array}$ & $\begin{array}{c}\text { Física } \\
\text { Ciencia } \\
\text { Ingeniería }\end{array}$ \\
\hline Guitar Hero & 2015 & $12+$ & $\begin{array}{c}\text { Rítmico } \\
\text { Multijugador }\end{array}$ & $\begin{array}{l}\text { Música } \\
\text { Ritmo }\end{array}$ \\
\hline Age of Empires & 2016 & $12+$ & $\begin{array}{l}\text { Estrategia a } \\
\text { tiempo real } \\
\text { Multijugador }\end{array}$ & $\begin{array}{l}\text { Historia } \\
\text { Economía }\end{array}$ \\
\hline Gone Home & 2013 & $16+$ & $\begin{array}{c}\text { Aventura } \\
\text { Exploración }\end{array}$ & $\begin{array}{l}\text { Lengua } \\
\text { Narrativa }\end{array}$ \\
\hline
\end{tabular}

Nota: Elaboración propia

Estos ejemplos han sido apoyados por artículos y/o estudios académicos, dado su potencial interés desde el punto de vista curricular (Darvasi, 2014; Farber, 2020; Gower \& McDowall, 2012; Parker, 2015; Ranalli \& Ritzko, 2013; Short, 2012; Squire \& Jenkins, 2003; Svensson, 2013; Tan et al., 2013). Sin embargo, el fin último de estos es el entretenimiento; no fueron específicamente diseñados con una finalidad pedagógica.

Respecto a los contenidos no curriculares impartidos por estos videojuegos, sus diseñadores destacan el desarrollo de habilidades que tienen como objetivo preparar a los estudiantes para el mundo actual. Tanto jugadores como docentes consideran que mediante los videojuegos desarrollan su capacidad para controlar la frustración, la creatividad, habilidades 
intelectuales, trabajo en equipo y coordinación visual-motriz (Martínez, 2019). Cabe destacar además el uso del inglés, idioma universal en los videojuegos.

También, es de interés el trabajo de Oceja \& González Fernández (2017), en el que se propone una clasificación de experiencias de juego para el desarrollo de competencias cívicas, que permiten a los individuos "participar en la vida civil teniendo una base de conocimiento sobre conceptos y estructuras sociales y políticas y un compromiso por la participación democrática activa" (p. 480). Este incluye varios ejemplos y análisis de videojuegos educativos, políticos y comerciales. En España, López Gómez y Rodríguez Rodríguez (2016) presentan una recopilación de proyectos pedagógicos realizados con videojuegos comerciales en las aulas españolas.

Aunque la utilización de videojuegos comerciales presenta una serie de ventajas, como la accesibilidad a los contenidos y su popularidad entre los estudiantes, para el buen funcionamiento de estas herramientas es necesaria la implicación por parte del docente, jugando un papel central en el proceso de aprendizaje, con su capacidad para integrar el uso del videojuego en el currículum (López Raventós, 2016).

\section{El aprendizaje basado en el diseño de juegos: una alternativa pedagógica}

Con el creciente interés por el medio de los videojuegos, los docentes han comenzado a tomar un rol activo en el desarrollo de videojuegos educativos, tratando de integrar las necesidades lúdicas y pedagógicas de los mismos (Dorado Gómez y Gewec Barujel, 2017). Destaca especialmente ProActive (2010), un proyecto a nivel europeo en el que los profesores toman el papel de desarrolladores de juegos en centros educativos de España e Italia. Analizando los resultados en diferentes escenarios de aprendizaje, se observaron las ventajas de este modelo, especialmente en lo referente a la vertiente pedagógica: i) el profesorado sabe qué contenidos tiene que integrar en el videojuego, por lo que puede incorporarlos desde las fases de diseño más tempranas y buscar mecánicas entretenidas para la transmisión de estos; ii) el videojuego es diseñado considerando aspectos clave como la evaluación, la adaptación a diferentes niveles y objetivos educativos, y la compatibilidad con las principales plataformas online de aprendizaje; iii) el proceso de diseño es divertido y enriquecedor para el docente, el cual se mantiene motivado y en constante formación y conexión con las nuevas tecnologías y el mundo en el que viven sus 
Percepciones de

los estudiantes
Percepciones de los estudiantes | Revista Virtual

Universidad Católica del Norte, 64, 5-40

ISSN: 0124-5821 (En línea)

alumnos; iv) diseñar videojuegos es un proceso cooperativo, en el que se comparten diversas perspectivas y enfoques creativos; requiere del trabajo de varias partes y permite la creación de un equipo formado por profesionales, docentes, investigadores e incluso alumnos, que se apoyan unos en otros para alcanzar un resultado.

Considerando estos beneficios, se buscaron modelos que integraran al alumno en el proceso de creación del videojuego. Los principales resultados fueron el aprendizaje basado en el desarrollo de videojuegos, que se fundamenta en el aprendizaje de conceptos de programación e informática mediante el desarrollo de un videojuego (Wu \& Inge Wang, 2012); y el aprendizaje basado en el diseño de juegos (Rugelj \& Lapina, 2019), el cual plantea una mayor efectividad del aprendizaje basado en juegos, si los alumnos toman un papel activo en el proceso de diseño. Los mismos autores insisten en la importancia del juego para la adquisición de nuevas habilidades y conocimientos, y defienden el diseño de videojuegos como una vía hacía el aprendizaje, si se utilizan herramientas adecuadas a la edad y capacidades de los alumnos.

Una de las principales limitaciones en el desarrollo de videojuegos por parte de docentes y estudiantes es la necesidad de conocimientos de programación (Swalwell, 2012). Sin embargo, en los últimos años ha habido un auge en la aparición de herramientas que permiten la creación de videojuegos sin necesidad de programar. Moreno-Ger et al. (2008) proponen precisamente la utilización de motores específicamente diseñados para este propósito, o la modificación de escenarios y niveles ya existentes en videojuegos comerciales que ofrecen herramientas para ello.

En este contexto, la recopilación realizada por Guerrero Cobos (2019) muestra algunas de las herramientas más utilizadas en educación. Estas destacan por su facilidad de acceso, carácter intuitivo para los usuarios, sin conocimientos avanzados de informática, un entorno atractivo para los alumnos y librerías de recursos. Vázquez-Cano y Ferrer Delgado (2015) estudian el uso de este tipo de herramientas en aulas de secundaria españolas: "El uso de una herramienta gratuita e intuitiva como Scratch permite que el alumno desarrolle de forma interdisciplinar diferentes contenidos de distintas asignaturas y trabaje simultáneamente diversas competencias básicas desde el razonamiento crítico" (p. 71). Los principales resultados muestran el desarrollo de la capacidad de resolución de problemas, el autoaprendizaje y el fomento del trabajo colaborativo.

Investigaciones previas (Alfonso Cuellar et al., 2018) han demostrado la eficacia del trabajo colaborativo mediado por las TIC y cómo, tanto docente como estudiantes, consideran que 
trabajar con las tecnologías de modo colaborativo mejora el aprendizaje (Martínez Jaramillo, 2018). Algunas ideas para este tipo de trabajos, propuestas por ProActive (2010), son: combinar el diseño de videojuegos con actividades complementarias; considerar que el aprendizaje puede tener lugar en las actividades de reflexión posteriores, y no exclusivamente en el tiempo de juego; planificar las actividades para que puedan desarrollarse dentro del tiempo disponible, dando la oportunidad a los alumnos de completarlas en casa cuando sea posible; relacionar los contenidos con el mundo real, equilibrando la fantasía con la educación; y abarcar los problemas de manera cooperativa.

Una vez realizada esta revisión de la literatura, esta investigación tiene como principal objetivo profundizar en el valor educativo del videojuego, desde la perspectiva de los estudiantes de Educación Secundaria. Concretamente: i) conocer los hábitos de juego de los estudiantes objeto de estudio, ii) profundizar en la valoración de los estudiantes sobre el uso de las TIC que hacen sus profesores, iii) abordar el impacto pedagógico de los videojuegos desde la perspectiva del alumnado, iv) recoger la opinión de los estudiantes sobre los videojuegos educativos comerciales, y v) valorar el interés de los alumnos por el diseño y desarrollo de videojuegos.

\section{Metodología}

\section{Método}

Para dar respuesta a los objetivos de este trabajo, se opta por seguir un enfoque cuantitativo, a través de una investigación no experimental y descriptiva, ya que no se ha manipulado ninguna variable, sino que se ha observado tal y como se presentan, para luego analizarlas mediante estadística descriptiva, permitiendo comprobar el comportamiento de estas respecto a la muestra (Bisquerra, 2004).

\section{Participantes}

Los participantes de esta investigación fueron estudiantes de un Instituto de Educación Secundaria Obligatoria -ESO- de la Comunidad Autónoma de Cantabria. La muestra seleccionada 
de manera no probabilística e intencional por conveniencia se compone de 55 alumnos de la ESO y Bachillerato. Todos los participantes poseían conocimientos previos sobre videojuegos. La tabla 2 recoge las características de la muestra.

\section{Tabla 2}

Datos identificativos de la muestra de estudiantes

\begin{tabular}{lcc}
\hline & Característica & Porcentaje \\
\hline Sexo & & \\
& Masculino & 49 \\
& Femenino & 51 \\
\hline Edad & & 23,64 \\
& 12 & 12,73 \\
& 13 & 9,09 \\
& 16 & 32,73 \\
& 18 & 20,0 \\
& 21 & 1,82 \\
\hline Curso & $1^{\circ}$ ESO & \\
\hline & $1^{\circ}$ Bachillerato & 40,0 \\
& $2^{\text {o }}$ Bachillerato & 36,36 \\
& & 23,64 \\
\hline
\end{tabular}

Nota: Elaboración propia.

Se observa que la mayor parte de los participantes son de $1^{\circ}$ de Bachillerato, y la menor, de $2^{\circ}$ de Bachillerato. No existe una diferencia destacable entre el número de hombres y mujeres encuestados.

\section{Instrumento}

Dadas las características de la investigación, se ha diseñado un único instrumento de evaluación diagnóstica dirigido a los estudiantes (ver Anexo 1). Este puede dividirse en cinco grandes bloques: Datos identificativos, profesores y nuevas tecnologías, impacto pedagógico de los videojuegos, perspectivas sobre los videojuegos educativos y perspectivas sobre el diseño y desarrollo de videojuegos. En cada bloque, a excepción del bloque de datos identificativos, se le 
presenta al alumno una escala tipo Likert con una serie de afirmaciones, que se deben responder del 1-4, siendo 1 "totalmente en desacuerdo" y 4 "totalmente de acuerdo".

Previamente a su cumplimentación, el cuestionario fue sometido a una validación de contenido, a través de la valoración del mismo por un panel de 3 jueces expertos, mediante la técnica Delphi, con representación del entorno educativo de la Comunidad Autónoma de Cantabria y de la industria del videojuego. Tras la revisión de las aportaciones de los jueces se realizaron las modificaciones pertinentes que permitieron reajustar la herramienta, añadiendo dos cuestiones relativas al tiempo de exposición de los estudiantes a los videojuegos, en el bloque de datos identificativos, y una pregunta abierta para conocer a qué títulos suelen jugar. El Alpha de Cronbach del instrumento, una vez eliminados los ítems sociodemográficos y las preguntas abiertas, fue muy favorable: .884

\section{Análisis de datos}

El análisis de los datos se realizó a través del programa estadístico SPSS v.22, permitiendo recoger los valores descriptivos y el comportamiento de los ítems que se presentan, a continuación, en la sección de resultados.

\section{Resultados}

A través de los análisis cuantitativos se ha dado respuesta a los diferentes objetivos planteados en la investigación:

\section{Conocer los hábitos de juego de los estudiantes objeto de estudio}

La tabla 3 muestra el tiempo diario que dedican los alumnos de Educación Secundaria a jugar a videojuegos, con propósitos lúdicos y educativos. El 54,55 \% de la muestra dedica menos de una 1 diaria; no obstante, hay casi un $10 \%$ que dedica en torno a 3 o más horas diarias. Respecto al tiempo que dedican los alumnos a los videojuegos educativos, el $87,27 \%$ señalan que menos de 1 hora diaria. 


\section{Tabla 3}

Resultados de los ítems 4 y 5 del bloque de datos identificativos

\begin{tabular}{lcccc}
\hline Ítem & $\begin{array}{c}\text { Menos } \\
\text { de 1 } \\
\text { hora } \\
\text { diaria }\end{array}$ & $\begin{array}{c}\text { En torno } \\
\text { a 1 hora } \\
\text { diaria }\end{array}$ & $\begin{array}{c}\text { En torno } \\
\text { a 2 } \\
\text { horas } \\
\text { diarias }\end{array}$ & $\begin{array}{c}\text { En torno } \\
\text { a 3 } \\
\text { horas } \\
\text { diarias o } \\
\text { más }\end{array}$ \\
\hline $\begin{array}{c}\text { 5. Indica aproximadamente el tiempo diario que } \\
\text { dedicas a jugar a videojuegos }\end{array}$ & $54,55 \%$ & $14,55 \%$ & $21,82 \%$ & $9,09 \%$ \\
\hline $\begin{array}{c}\text { 6. Indica aproximadamente el tiempo diario que } \\
\text { dedicas a jugar a videojuegos con propósitos } \\
\text { educativos }\end{array}$ & $87,27 \%$ & $7,27 \%$ & $1,82 \%$ & $3,64 \%$ \\
\hline Nota: Elaboración propia & & & & \\
\hline
\end{tabular}

También, en relación con este objetivo, en la última cuestión del bloque se pide a los estudiantes que indiquen a qué videojuegos suelen jugar. De las respuestas recibidas, los títulos más repetidos fueron Fortnite, la saga Call Of Duty, Gran Theft Auto V y juegos deportivos como Fifa y NBA. Se encontraron diferencias entre el sexo masculino y el femenino, destacando exclusivamente entre las mujeres títulos como Just Dance y Animal Crossing. Destaca que todos estos títulos corresponden a videojuegos comerciales.

\section{Profundizar en la valoración de los estudiantes sobre el uso de las TIC que hacen sus profesores}

En la tabla 4 se pueden observar los resultados relacionados con el objetivo 2, que corresponde al bloque B del cuestionario. Un 45,45 \% de los alumnos está de acuerdo con que sus profesores utilizan las TIC en sus clases, pero un 69,09\% está totalmente de acuerdo con que les gustaría que hicieran más uso de ellas, y alrededor de la mitad, el 58,18 \%, con que les gustaría que sus profesores utilizaran videojuegos en sus clases. Actualmente, el $100 \%$ de los alumnos confirman que sus profesores no utilizan los videojuegos como recurso educativo, y los mayores porcentajes, respecto al desarrollo de materiales educativos empleando las nuevas tecnologías, confirman el interés de los alumnos por una mayor digitalización en las aulas. Por otro lado, se 
presentan la media y la desviación típica para comprender mejor los resultados. Las puntuaciones medias más elevadas recaen en los ítems 8, 10 y 11.

Tabla 4

Resultados del bloque sobre profesores y nuevas tecnologías

\begin{tabular}{|c|c|c|c|c|c|c|}
\hline \multirow[b]{2}{*}{ Ítem } & \multicolumn{4}{|c|}{ Frecuencias } & \multicolumn{2}{|c|}{ Descriptivos } \\
\hline & 1 & 2 & 3 & 4 & Media & Desviación \\
\hline $\begin{array}{l}\text { 7. Mis profesores utilizan } \\
\text { las nuevas tecnologías en } \\
\text { sus clases }\end{array}$ & $9,09 \%$ & $30,91 \%$ & $45,45 \%$ & $14,55 \%$ & 2,65 & ,844 \\
\hline $\begin{array}{l}\text { 8. Me gustaría que mis } \\
\text { profesores hicieran más uso } \\
\text { de las nuevas tecnologías en } \\
\text { sus clases }\end{array}$ & $3,64 \%$ & $12,73 \%$ & $14,55 \%$ & $69,09 \%$ & 3,49 & ,858 \\
\hline $\begin{array}{l}\text { 9. Mis profesores utilizan } \\
\text { videojuegos en sus clases }\end{array}$ & $100,00 \%$ & $0,0 \%$ & $0,0 \%$ & $0,0 \%$ & 1,00 & ,000 \\
\hline $\begin{array}{l}\text { 10. Me gustaría que los } \\
\text { profesores } \\
\text { videojuegos en sus clases }\end{array}$ & $16,36 \%$ & $7,27 \%$ & $18,18 \%$ & $58,18 \%$ & 3,18 & 1,140 \\
\hline $\begin{array}{l}\text { 11. Me gustaría que los } \\
\text { profesores desarrollaran sus } \\
\text { propios materiales } \\
\text { educativos empleando las } \\
\text { nuevas tecnologías }\end{array}$ & $5,45 \%$ & $14,55 \%$ & $32,73 \%$ & $47,27 \%$ & 3,22 & ,896 \\
\hline
\end{tabular}

Nota: Elaboración propia.

\section{Abordar el impacto pedagógico de los videojuegos desde la perspectiva del alumnado}

En relación con el objetivo 3, los resultados obtenidos en el bloque $\mathrm{C}$ del cuestionario se muestran en la tabla 5. Los ítems con los que los estudiantes están más de acuerdo son aquellos relacionados con una mejora de las habilidades del manejo de las TIC y el desarrollo de la creatividad, los cuales corresponden con las medias más altas. También, se destaca el aumento de la motivación, con un $38.18 \%$ de alumnos totalmente de acuerdo. Las medias más bajas corresponden al desarrollo de habilidades profesionales y a la mejora de la capacidad de comunicación, con tan solo un $16.36 \%$ y $20 \%$ de alumnos totalmente de acuerdo, respectivamente. 


\section{Tabla 5}

Resultados del bloque sobre el impacto pedagógico de los videojuegos

\begin{tabular}{lcccccc}
\hline & \multicolumn{2}{c}{ Frecuencias } & \multicolumn{2}{c}{ Descriptivos } \\
\hline \multicolumn{1}{c}{ Ítem } & 1 & 2 & 3 & 4 & Media & Desviación \\
\hline $\begin{array}{l}\text { 12. Los videojuegos aumentan } \\
\text { mi motivación }\end{array}$ & $20,00 \%$ & $18,18 \%$ & $23,64 \%$ & $38,18 \%$ & 2,80 & 1,161 \\
\hline $\begin{array}{l}\text { 13. Los videojuegos mejoran mis } \\
\text { habilidades en el manejo de la } \\
\text { información y las nuevas } \\
\text { tecnologías }\end{array}$ & $10,91 \%$ & $14,55 \%$ & $27,27 \%$ & $47,27 \%$ & 3,11 & 1,031 \\
\hline $\begin{array}{l}\text { 14. Los videojuegos mejoran mi } \\
\text { capacidad de aprendizaje }\end{array}$ & $18,18 \%$ & $25,45 \%$ & $32,73 \%$ & $23,64 \%$ & 2,62 & 1,045 \\
\hline $\begin{array}{l}\text { 15. Los videojuegos mejoran mi } \\
\text { capacidad de comunicación }\end{array}$ & $25,45 \%$ & $29,09 \%$ & $25,45 \%$ & $20,00 \%$ & 2,40 & 1,082 \\
\hline $\begin{array}{l}\text { 16. Los videojuegos mejoran mi } \\
\text { capacidad de colaboración }\end{array}$ & $21,82 \%$ & $36,36 \%$ & $16,36 \%$ & $25,45 \%$ & 2,45 & 1,102 \\
\hline $\begin{array}{l}\text { 17. Los videojuegos mejoran mi } \\
\text { capacidad de resolución de } \\
\text { problemas }\end{array}$ & $20,00 \%$ & $23,64 \%$ & $29,09 \%$ & $27,27 \%$ & 2,64 & 1,095 \\
\hline $\begin{array}{l}\text { 18. Los videojuegos me ayudan a } \\
\text { desarrollar } \\
\text { profesionales }\end{array}$ & $21,82 \%$ & $36,36 \%$ & $25,45 \%$ & $16,36 \%$ & 2,36 & 1,007 \\
\hline $\begin{array}{l}\text { 19. Los videojuegos me ayudan a } \\
\text { desarrollar mi creatividad }\end{array}$ & $5,45 \%$ & $9,09 \%$ & $43,64 \%$ & $41,82 \%$ & 3,22 &, 832 \\
\hline $\begin{array}{l}\text { hota: Elaboracion propia. } \\
\text { nades }\end{array}$ & & & & & \\
\hline
\end{tabular}

Nota: Elaboración propia.

\section{Recoger la opinión de los estudiantes sobre los videojuegos educativos}

En la tabla 6 se muestran los resultados relacionados con el objetivo 4, que corresponde al bloque D del cuestionario. Con una media de 2.89 y los porcentajes más elevados en las opciones 3 y 4, los alumnos parecen estar de acuerdo en que los videojuegos educativos les aportan nuevos conocimientos. Respecto al ítem 2, "los videojuegos educativos son innovadores", un $54.44 \%$ respondió estar en desacuerdo. Destaca el desconocimiento de ejemplos de videojuegos educativos por parte de los alumnos, habiendo respondido tan solo un 5,45\% que están totalmente de acuerdo con la afirmación correspondiente, y siendo el ítem con la media más baja. 
Tabla 6

Resultados del bloque sobre perspectivas sobre los videojuegos educativos

\begin{tabular}{|c|c|c|c|c|c|c|}
\hline \multirow[b]{2}{*}{ Ítem } & \multicolumn{4}{|c|}{ Frecuencias } & \multicolumn{2}{|c|}{ Descriptivos } \\
\hline & 1 & 2 & 3 & 4 & Media & Desviación \\
\hline $\begin{array}{l}20 . \quad \text { Los videojuegos } \\
\text { educativos son divertidos }\end{array}$ & $18,18 \%$ & $38,18 \%$ & $34,55 \%$ & $9,09 \%$ & 2,35 & ,886 \\
\hline $\begin{array}{l}21 . \quad \text { Los videojuegos } \\
\text { educativos son innovadores }\end{array}$ & $10,91 \%$ & $54,55 \%$ & $27,27 \%$ & $7,27 \%$ & 2,31 & ,767 \\
\hline $\begin{array}{l}22 . \quad \text { Los videojuegos } \\
\text { educativos me aportan nuevos } \\
\text { conocimientos }\end{array}$ & $7,27 \%$ & $27,27 \%$ & $34,55 \%$ & $30,91 \%$ & 2,89 & ,936 \\
\hline \begin{tabular}{llr}
$23 . \quad$ Los & \multicolumn{2}{c}{ videojuegos } \\
educativos & mejoran & mis \\
habilidades & & \\
\end{tabular} & $10,91 \%$ & $40,00 \%$ & $32,73 \%$ & $16,36 \%$ & 2,55 & ,899 \\
\hline $\begin{array}{l}24 . \quad \text { Los videojuegos } \\
\text { educativos son atractivos }\end{array}$ & $32,73 \%$ & $38,18 \%$ & $27,27 \%$ & $1,82 \%$ & 1,98 & ,828 \\
\hline $\begin{array}{l}25 . \quad \text { Conozco } \\
\begin{array}{l}\text { ejemplos de } \\
\text { ejuchos } \\
\text { educativos }\end{array}\end{array}$ & $49,09 \%$ & $36,36 \%$ & $9,09 \%$ & $5,45 \%$ & 1,71 & ,854 \\
\hline
\end{tabular}

Nota: Elaboración propia.

Valorar el interés de los alumnos por el diseño y desarrollo de videojuegos

En la tabla 7 se pueden observar los resultados del bloque E del cuestionario. Con las medias más elevadas, y por encima del punto medio de la escala, los alumnos revelan interés por dedicarse a una profesión relacionada con las STEAM, y por incorporar el diseño y desarrollo de videojuegos durante las clases. No existe una tendencia clara respecto al interés por el diseño y desarrollo de videojuegos y la relación entre el interés por una materia y la creación de un videojuego sobre la misma. Sin embargo, con un porcentaje del $52.73 \%$, en ambos casos, los alumnos están totalmente en desacuerdo, respecto a haber tenido experiencias previas en el diseño y desarrollo de videojuegos y el interés de dedicarse a ello. 
Percepciones de

los estudiantes
Percepciones de los estudiantes | Revista Virtual

Universidad Católica del Norte, 64, 5-40

ISSN: 0124-5821 (En línea)

Tabla 7

Resultados del bloque sobre perspectivas sobre el diseño y desarrollo de videojuegos

\begin{tabular}{|c|c|c|c|c|c|c|}
\hline & \multicolumn{4}{|c|}{ Frecuencias } & \multicolumn{2}{|c|}{ Descriptivos } \\
\hline Ítem & 1 & 2 & 3 & 4 & Media & Desviación \\
\hline $\begin{array}{l}\text { 26. Me gustaría dedicarme a } \\
\text { una profesión relacionada con } \\
\text { las STEAM (Ciencias, } \\
\text { Tecnología, Ingeniería, Arte y } \\
\text { Matemáticas) }\end{array}$ & $23,64 \%$ & $20,00 \%$ & $20,00 \%$ & $36,36 \%$ & 2,69 & 1,200 \\
\hline $\begin{array}{llll}27 . & \text { Tengo } & \text { interés por } & \text { el } \\
\text { diseño y } & \text { desarrollo } & \text { de } \\
\text { videojuegos } & & & \\
\end{array}$ & $21,82 \%$ & $27,27 \%$ & $21,82 \%$ & $29,09 \%$ & 2,58 & 1,134 \\
\hline $\begin{array}{l}\text { 28. He tenido experiencias } \\
\text { previas en el diseño y } \\
\text { desarrollo de videojuegos }\end{array}$ & $52,73 \%$ & $20,00 \%$ & $18,18 \%$ & $9,09 \%$ & 1,84 & 1,032 \\
\hline $\begin{array}{l}\text { 29. Me gustaría dedicarme al } \\
\text { diseño y desarrollo de } \\
\text { videojuegos }\end{array}$ & $52,73 \%$ & $18,18 \%$ & $14,55 \%$ & $14,55 \%$ & 1,91 & 1,127 \\
\hline $\begin{array}{l}30 . \text { Diseñar videojuegos } \\
\text { sobre una materia aumentaría } \\
\text { mi interés sobre la misma }\end{array}$ & $25,45 \%$ & $20,00 \%$ & $34,55 \%$ & $20,00 \%$ & 2,49 & 1,086 \\
\hline $\begin{array}{l}\text { 31. Me gustaría incorporar el } \\
\text { diseño y desarrollo de } \\
\text { videojuegos durante las clases }\end{array}$ & $18,18 \%$ & $18,18 \%$ & $25,45 \%$ & $38,18 \%$ & 2,84 & 1,135 \\
\hline
\end{tabular}

Nota: Elaboración propia.

\section{Valoraciones del alumnado}

Finalmente, en el cuestionario se presenta una última pregunta abierta en la que se pedía a los estudiantes que añadieran comentarios relacionados con la temática. De las respuestas obtenidas, se han seleccionado 3 como relevantes, dado que abarcan opiniones diversas sobre aspectos que han sido tratados en este trabajo.

En mi opinión, los videojuegos educativos tienen grandes ventajas. Los niños de hoy en día se pasan el día en casa encerrados jugando videojuegos, violentos, sobre todo, y creo que, si se les implanta la costumbre de jugar a videojuegos educativos, además de hacerlos atractivos para ellos, disminuiría la violencia y los niños aprenderían de verdad, ya que, por experiencia propia, en las clases se suele desconectar rápidamente y, sin embargo, los videojuegos requieren de más atención. (Respuesta 1) 
El problema con los videojuegos educativos es que estos no son compatibles con todos los rangos de edad, es decir, suelen estar enfocados a un público con un rango de edad bastante menor, y eso en otros años no atrae mucho. (Respuesta 2)

Los videojuegos son para mí una forma de diversión y de cooperación. (Respuesta 3)

\section{Discusión}

Los resultados de esta investigación han demostrado que los alumnos de secundaria tienen interés por los videojuegos y las nuevas tecnologías. Aunque no haya indicios de una exposición prolongada en la mayor parte de casos, alrededor de la mitad de los encuestados declararon jugar en torno a 1 y 3 horas diarias a videojuegos. Esto apoya el estudio realizado por la AEVI (2019), que sitúa los adolescentes entre los grupos de edad que más juegan a videojuegos. Concretamente, los jugadores españoles dedican una media de 6.7 horas semanales a los videojuegos. También, cabe destacar la diferencia de hábitos encontradas entre sexos en lo referente a qué títulos jugar. Los estudios ya indicaban indicios de estas diferencias, aunque estos se centraran en la preferencia por diferentes plataformas de juego (Del Barrio Fernández, 2014).

Por otro lado, aunque las TIC hayan sido incorporadas en el proceso educativo y los profesores hagan uso de estas en las clases, a los alumnos les gustaría que este uso se incrementara. Además, no hay indicios de que se utilicen videojuegos durante las clases, aunque los profesores los consideran un medio de carácter lúdico y dinámico que puede activar la motivación y efectividad del aprendizaje (AEVI, 2019). Los alumnos también confirmaron su interés en que los profesores utilicen videojuegos durante las clases y en el desarrollo de materiales educativos empleando las nuevas tecnologías.

En general, hay un amplio desconocimiento sobre ejemplos de videojuegos educativos. Los alumnos consideran que estos tienen el potencial de aportarles nuevos conocimientos, pero no hay datos significativos respecto a si estos son divertidos o innovadores. Respecto a su atractivo, los resultados van en línea con los estudios realizados sobre las limitaciones de los videojuegos educativos (Dorado Gómez y Gewec Barujel, 2017). Aunque la opinión general es más favorable respecto a la mejora de habilidades (Martínez, 2019), tampoco hay un consenso claro sobre su uso 
en las aulas. De nuevo, esto se remitiría a la falta de videojuegos educativos enfocados a la Educación Secundaria.

A pesar de ello, los alumnos tienen su propia opinión respecto a los beneficios de jugar a videojuegos. Los estudiantes coinciden en la mejora de su dominio de las nuevas tecnologías, el aumento de la motivación y en el desarrollo de la creatividad (Garmen et al., 2019), pero no hay una opinión clara sobre el incremento de sus capacidades de comunicación, colaboración, aprendizaje, resolución de problemas ni de sus habilidades profesionales (Vázquez-Cano y Ferrer Delgado, 2015).

Se han encontrado algunos contrastes respecto a las experiencias previas con el diseño y desarrollo de videojuegos. Los alumnos demuestran interés por las disciplinas STEAM y escogerían una profesión relacionada con alguna de sus ramas, lo cual apoya el trabajo realizado por Yepes Miranda (2020). No obstante, la mayoría de las estudiantes no ha tenido ninguna experiencia previa, aunque el estudio conducido por la empresa ConMasFuturo revela la preferencia de los alumnos de secundaria por las extraescolares de desarrollo de aplicaciones, programación web y robótica (González, 2015). El alumnado no ha expresado su interés por el diseño y desarrollo de videojuegos.

Respecto a las valoraciones personales de los alumnos, parecen coincidir en que los videojuegos pueden ser una manera divertida de aprender, si los contenidos se presentan de manera atractiva y adaptada al rango de edad de los estudiantes de secundaria. Se reafirman las ideas de Giraldo Plaza y Mateus (2010) sobre las diferencias entre lo que la industria considera un videojuego educativo y los videojuegos que quieren los alumnos. Se destaca también una valoración sobre la necesidad de que sus contenidos no sean violentos.

\section{Conclusiones}

En este trabajo se ha llevado a cabo un estudio de actualidad sobre el valor educativo del videojuego, su diseño como estrategia pedagógica en el aula y una investigación en torno a la percepción de los alumnos de secundaria sobre los videojuegos y a sus hábitos de consumo. Las nuevas tecnologías ya han llegado a las aulas y, con ellas, los docentes deben adaptarse a las formas de aprender de las nuevas generaciones, las cuales distan de los métodos tradicionales. Aunque los 
centros educativos cuentan con los recursos tecnológicos, existe una creciente necesidad de utilizar esta tecnología para aplicar metodologías innovadoras, capaces de motivar y estimular a los alumnos.

Los estudiantes de secundaria han revelado sus hábitos de juego, así como sus opiniones respecto a los videojuegos educativos y qué beneficios pueden obtener de ellos. Los alumnos los consideran como un elemento que podría aumentar su motivación, creatividad y conocimientos, pero no hay indicios claros de que los videojuegos puedan incrementar su interés por los contenidos impartidos en las diferentes materias ni un interés evidente por el diseño y desarrollo de videojuegos. Aunque hay un interés por las STEAM, este ha sido inferior al esperado.

A pesar de que videojuegos son un medio de interés para los adolescentes, hay una falta de exposición a ellos en los centros educativos. Uno de los aspectos en el que los alumnos han mostrado mayor grado de acuerdo es en que les gustaría que sus profesores hicieran un mayor uso de las nuevas tecnologías en sus clases. Dada la ausencia en el mercado de videojuegos educativos adaptados a las necesidades de esta etapa educativa, el uso de videojuegos comerciales en el aula y el desarrollo de materiales educativos basados en las TIC serían los medios más adecuados para aprovechar los beneficios de los videojuegos en las aulas de secundaria.

De hecho, una de las mayores limitaciones para la realización de este trabajo ha sido la dificultad para encontrar ejemplos de videojuegos educativos diseñados para los estudiantes de secundaria, siendo este un nicho del sector aún por explotar. Los ejemplos encontrados están orientados a la investigación y no se ha desarrollado en profundidad el aspecto gráfico o la jugabilidad, o están obsoletos. También, en el caso de experiencias de creación de videojuegos en las aulas, los resultados no pueden competir con los videojuegos comerciales, a pesar de los beneficios explorados. En el caso de estos, sí se han encontrado estudios respaldando su uso en las aulas.

Los prejuicios existentes respecto a los videojuegos y la problemática que los envuelve también han generado que muchos de los resultados obtenidos durante la búsqueda de la literatura estén relacionados con cuestiones como la adicción y la agresividad. Sin embargo, estos problemas son propios de un uso inadecuado del medio. No hay estudios que demuestren que una exposición moderada a los videojuegos tenga consecuencias físicas ni psicológicas sobre los jóvenes. Por 
Percepciones de

los estudiantes
Percepciones de los estudiantes | Revista Virtual

Universidad Católica del Norte, 64, 5-40

ISSN: 0124-5821 (En línea)

tanto, esto invita a una reflexión respecto al papel de las familias en moderar y regular esta exposición.

Por otro lado, dado el tamaño de la muestra, existe la necesidad de realizar un estudio a mayor escala para obtener resultados determinantes. Del mismo modo, no se descarta que el contexto del instituto en el que se ha realizado la recogida de datos haya podido influir en los resultados. Aunque los participantes del estudio han tenido experiencias previas con videojuegos, habría que investigar el impacto de las nuevas tecnologías sobre institutos de entornos rurales y urbanos con diferente nivel sociocultural. Igualmente, sería muy interesante completar este estudio predominantemente cuantitativo con la recogida de datos cualitativos, a través de Focus Group.

Con la perspectiva de futuros trabajos y líneas de investigación, se plantea el desarrollo de una propuesta educativa que implemente el uso del videojuego en diferentes asignaturas y niveles de secundaria, para estudiar de manera directa su impacto sobre los alumnos y los resultados sobre el aprendizaje. Por otro lado, sería notable estudiar la creación de videojuegos en el aula, así como la necesidad de establecer más programas de formación en alta especialidad TIC en los centros educativos, con el objetivo de formar al profesorado y acercar los nuevos avances tecnológicos a los estudiantes.

Finalmente, para asegurar un buen uso de estas tecnologías, es importante educar en cómo manejarlas, concienciando a padres y docentes de las posibilidades que ofrecen los videojuegos; pero, también, de lo fundamental que es obedecer las recomendaciones respecto a los tiempos de exposición y respetar las herramientas como el PEGI (s.f.), que permiten adecuar los contenidos a los que debería ser expuesto cada grupo de edad y tomar decisiones responsables. 


\section{Referencias}

AEVI. (2019). La industria del videojuego en España. Anuario 2019. http://www.aevi.org.es/web/wp-content/uploads/2020/04/AEVI-ANUARIO-2019.pdf

Akçayir, G., \& Akçayır, M. (2018). The flipped classroom: A review of its advantages and challenges. Computers \& Education, 126, 334-345. https://doi.org/10.1016/j.compedu.2018.07.021

Alfonso Cuellar, J. J., Mancera Valetts, L. P. y Cárdenas, Y. (mayo-agosto, 2018). Trabajo colaborativo mediado por las TIC: estrategia para el fomento de la competencia argumentativa. Revista Virtual Universidad Católica del Norte, (54), 41-55. https://revistavirtual.ucn.edu.co/index.php/RevistaUCN/article/view/981/1430

Barbosa, A. F., Pedro, P. N., Dias, J. A., \& Silva, F. G. (2014). A New Methodology of Design and Development of Serious Games. International Journal of Computer Games Technology, 1-8. https://doi.org/10.1155/2014/817167

Bernaschina Cuadra, D. (2019). Las TIC y Artes mediales: La nueva era digital en la escuela inclusiva. Alteridad, 14(1), 40-52. https://doi.org/10.17163.alt.v14n1.2019.03

Bisquerra, R. (2004). Metodología de la investigación educativa. La Muralla.

Buiza-Aguado, C., García-Calero, A., Alonso-Cánovas, A., Ortiz-Soto, P., Guerrero-Díaz, M., González-Molinier, M., y Hernández-Medrano, I. (2017). Los videojuegos: una afición con implicaciones neuropsiquiátricas. Psicología Educativa, 23(2), 129-136. https://doi.org/10.1016/j.pse.2017.05.001

Burbules, N. C. (2012). El aprendizaje ubicuo y el futuro de la enseñanza. Encuentros sobre Education, (13), 3-14. https://dialnet.unirioja.es/servlet/articulo?codigo=4100463

Calvo González, S., y San Fabián, J. L. (2018). Redes Sociales y Socialización Afectiva de las Personas Jóvenes: Necesidades Docentes en Educación Secundaria Obligatoria. REICE. Revista Iberoamericana sobre Calidad, Eficacia y Cambio en Educación, 16(2), 5-20. https://doi.org/10.15366/reice2018.16.2.001

Conde-Cortabitarte, I., Rodríguez-Hoyos, C., y Calvo-Salvador, A. (2020). Potencialidades y límites educativos de los videojuegos activos: una investigación basada en entrevistas a 
docentes de Educación Física. Cultura, Ciencia y Deporte, 15(43), 43-52. http://dx.doi.org/10.12800/ccd.v15i43.1398

Corvos, C. A., Bizzozero, B., Pintos-Toledo, E., Fernández-Gimánez, S., y Brazo-Sayavera, J. (2020). Beneficios de los videojuegos activos sobre parámetros de aptitud física relacionada con la salud: un comentario en tiempos de cuarentena. Revista Médica del Uruguay, 36(4), 234-248. https://doi.org/10.29193/RMU.36.4.11

Darvasi, P. (2014). Gone Home Lesson 1: Writes of Passage, Annotating a Foyer and Screenshot Citations. http://www.ludiclearning.org/2014/03/29/annotating-the-foyer-towards-aclose-playing-of-gone-home/

De la Horra Villacé, I. (2016). Realidad aumentada, una revolución educativa. EDMETIC, 6(1), 922. https://doi.org/10.21071/edmetic.v6i1.5762

Del Barrio Fernández, Á. (2014). Los Adolescentes y el uso de Teléfonos Móviles y Videojuegos. International Journal of Developmental and Educational Psychology, 3(1), 563-570. https://doi.org/10.17060/ijodaep.2014.n1.v3.536

Del Corral Núñez-Flores, T. (2018). Eficacia de un programa a largo plazo de rehabilitación respiratoria mediante plataforma de videojuegos en pacientes con fibrosis quística. Universidad de Barcelona.

Depping, A.E., \& Mandryk, R. (2017). Cooperation and Interdependence: How Multiplayer Games Increase Social Closeness. Proceedings of the Annual Symposium on ComputerHuman Interaction in Play, 449-461. https://dl.acm.org/doi/10.1145/3116595.3116639

Dorado Gómez, S., y Gewec Barujel, A. (2017). El profesorado español en la creación de materiales didácticos: los videojuegos educativos. Digital Education Review, (31), 176195. https://revistes.ub.edu/index.php/der/article/view/17373

Farber M. (2020). How to Find Games for Classroom Learning. https://www.edutopia.org/article/how-find-games-classroom-learning

García Cernaz, S. (2017). Videojuegos y violencia: Una revisión de la línea de investigación de los efectos. Revista de la Escuela de Ciencias de la Educación, 13(1), 149-165. https://doi.org/10.35305/rece.v1i13.329

García González, M. (2015). Aprendizaje basado en juegos serios como herramienta de la educación para todos. Universidad de Salamanca. 
Garmen, P., Rodríguez, C., García-Redondo, P., y San Pedro, J. (2019). Inteligencias múltiples y videojuegos: evaluación e intervención con software TOI. Comunicar, 27(58), 96-104. https://doi.org/10.3916/C58-2019-09

Giraldo Plaza, J., y Mateus, S. P. (2010). Aprendizaje de la programación orientada a objetos a través del diseño de juegos de vídeo. Revista Digital Sociedad de la Información, (22). http://www.sociedadelainformacion.com/22/juegosvideo.pdf

González I. (2015). Estudio sobre Extraescolares y Nuevas Tecnologías. https://www.conmasfuturo.com/la-programacion-la-robotica-o-el-diseno-web-son-lasextraescolares-preferidas-de-los-ninos-en-primaria-y-la-eso/

González, J., y Martín, S. (2019). Prácticas educativas mediadas por TIC. Un análisis de la metodología del profesorado a través del Programa Escuela 2.0. REIDOCREA, 8(2), 7585. http://dx.doi.org/10.30827/Digibug.58501

Gower, L., \& McDowall, J. (2012). Interactive music video games and children`s musical development. British Journal of Music Education, 29, 91-105. https://doi.org/10.1017/S0265051711000398

Guerrero Cobos, A. (2019). Motores de videojuegos para el aprendizaje en el contexto escolar: Uso de Roblox en Educación Plástica, Visual y Audiovisual (Tesis de maestría). Unversidad de La Laguna.

Jeong, H., Hmelo-Silver, C. E., \& Jo, K. (2019). Ten years of Computer-Supported Collaborative Learning: A meta-analysis of CSCL in STEM education during 2005-2014. Educational Research Review, 28. https://doi.org/10.1016/j.edurev.2019.100284

Holguin, J., Taxa, F., Flores, R., y Olaya, S. (2020). Proyectos educativos de gamificación por videojuegos: desarrollo del pensamiento numérico y razonamiento escolar en contextos vulnerables. EDMETIC, Revista de Educación Mediática y TIC, 9(1), 80-103 https://doi.org/10.21071/edmetic.v9i1.12222

Kapp, K. M. (2013). The gamification of learning and instruction fieldbook: Ideas into practice. John Wiley \& Sons.

Lacasa, P., Delcastillo, H., Cortés, S., García-Varela, A., Monjelat, N., y Nogueiras, G. (2010). Informe de Investigación: Videojuegos Comerciales y Aprendizaje Escolar: Análisis de las 
Percepciones de

los estudiantes
Percepciones de los estudiantes | Revista Virtual

Universidad Católica del Norte, 64, 5-40

ISSN: 0124-5821 (En línea)

creencias del alumnado de Educación Secundaria Obligatoria. http://www.aprendeyjuegaconea.com/files/informe_UAH_2010.pdf

Ledo Rubio, A. I., de la Gándara Martín, J. J., García Alonso, M. I., y Gordo Seco, R. (2016). Videojuegos y Salud Mental: De la adicción a la rehabilitación. Cuadernos de Medicina $\begin{array}{llllll}\text { Psicosomática } & y & \text { Psiquiatría de }\end{array}$ https://investigacion.ubu.es/documentos/5db18061299952477238ab01

López Gómez, S., y Rodríguez Rodríguez, J. (2016). Experiencias didácticas con videojuegos comerciales en las aulas españolas. Revista DIM: Didáctica, Innovación y Multimedia, (33). https://ddd.uab.cat/pub/dim/dim_a2016m3n33/dim_a2016m3n33a12.pdf

López Raventós, C. (2016). El videojuego como herramienta educativa. Posibilidades y problemática acerca de los serious games. Apertura, 8(1), 136-151. http://www.udgvirtual.udg.mx/apertura/index.php/apertura/article/view/825

Marengo, L., Herrera, L., Coutinho , V., Rotela, G., y Strahler, T. (2015). ¿Gamer o adicto? Revisión narrativa de los aspectos psicológicos de la adicción a los videojuegos. Revista Neuropsicologia Latinoamericana, 7(3),1-12. https://www.neuropsicolatina.org/index.php/Neuropsicologia_Latinoamericana/article/vi ew/266/182

Martínez Jaramillo, H. A. (2018). Usabilidad de las TIC en la UNAD como estrategia pedagógica y didáctica. Revista Virtual Universidad Católica del Norte, 54, 87-113. https://revistavirtual.ucn.edu.co/index.php/RevistaUCN/article/view/985/1433

Martínez, J. (2019). Percepciones de estudiantes y profesores acerca de las competencias que desarrollan los videojuegos. Revista de Investigación Educacional Latinoamericana, 56(2), 1-21. https://doi.org/10.7764/PEL.56.2.2019.3

Ministerio de Educación y Formación Profesional. (15 de mayo de 2020). El 96,8 \% de las aulas españolas contaba con conexión a internet en el curso 2018-2019. http://www.educacionyfp.gob.es/prensa/actualidad/2020/05/20200515estadisticacomunicaciones.html

Moreno-Ger, P., Burgos, D., Martínez-Ortiz, I., Sierra, J. L., \& Fernández-Manjón, B. (2008). Educational game design for online education. Computers in Human Behavior, 24(6), 2530-2540. https://doi.org/10.1016/i.chb.2008.03.012 
Nallar, D. A. (2016). Diseño de juegos. IEEE Biennial Congress of Argentina (ARGENCON), 13. https://doi.org/10.1109/ARGENCON.2016.7585326

Navas, M., y Postigo, A. Y. (2020). Análisis de las posibilidades educativas de videojuegos. Más allá de la alarma social. En F. J. Ruiz, N. Quero, M. Cebrián, P. Hernández (Coords.), Tecnologías emergentes y estilos de aprendizaje para la enseñanza (pp. 209-222). Junta de Andalucía. https://dialnet.unirioja.es/servlet/articulo?codigo=7408977

Núñez-Barriopedro, E., Sanz-Gómez, I., y Ravina-Ripoll, R. (2020). Los videojuegos en la educación: Beneficios y perjuicios. Revista electrónica EDUCARE, 24(2), 1-18. https://doi.org/10.15359/ree.24-2.12

OCDE. (2018). Programa para la Evaluación Internacional de Estudiantes (PISA). Resultados de PISA 2018. https://www.oecd.org/pisa/publications/PISA2018_CN_esp_ESP.pdf

Oceja, J., \& González Fernández, N. (2017). Classification of Game Experiences to Promote Civic Competence in the Context of Informal Learning. Proceedings of The 11th European Conference on Game-Based 480-486. https://www.researchgate.net/publication/320189317_Classification_of_Game_Experienc es_to_Promote_Civic_Competence_in_the_Context_of_Informal_Learning/figures?lo=1

Padilla Zea, N. (2011). Metodología para el diseño de videojuegos educativos sobre una arquitectura para el análisis del aprendizaje colaborativo. (Tesis de doctorado). Universidad de Granada. http://digibug.ugr.es/bitstream/10481/19440/1/20058287.pdf

Padilla Zea, N., Paderewski, P., Gutiérrez Vela, F., y Medina, N. M. (2012). Una arquitectura para el desarrollo de videojuegos educativos con actividades colaborativas. En A. Ruíz y L. Iribarne (Eds.), Jornadas SISTEDES'2012 (pp. 144-158). Universidad de Almería.

Pardo Baldoví, M. I. (2019). El aula del futuro: más allá de la introducción de tecnología. En Redine (Ed.), 3rd International Virtual Conference on Educational Research and Innovation (p. 40). Redine. http://www.civinedu.org/wpcontent/uploads/2019/12/CIVINEDU2019.pdf

Parker, N. D. (2015). Utilizing Scribblenauts to increase reading comprehension and improve literacy skills of third grade students (Doctoral Dissertation). East Carolina University.

PEGI. (s.f.). Pan European Game Information. http://www.pegi.info/es/index/ 
Ponce-Blandón, J. A., Espejel-Hernández, I., Romero-Martín, M., Lomas-Campos, M. del M., Jiménez-Picón, N., \& Gómez-Salgado, J. (2020). Videogame-related experiences among $\begin{array}{lllll}\text { regular adolescent } & \text { gamers. }\end{array}$ https://doi.org/10.1371/journal.pone.0235327

Prensky, M. (2011). Enseñar a nativos digitales. Ediciones SM.

Prescott, A. T., Sargent, J. D., \& Hull, J. G. (2018). Metaanalysis of the relationship between violent video game play and physical aggression over time. PNAS Proceedings of the National Academy of Sciences of the United States of America, 115(40), 98829888. https://doi.org/10.1073/pnas.1611617114

ProActive. (2010). Cuando los profesores diseñan juegos. Recomendaciones para prácticas creativas de aprendizaje basado en juegos. http://www.ub.edu/euelearning/proactive/documents/ProActive_guidelines_ES.pdf

Quesada, A., y Tejedor, S. (2016). Aplicaciones educativas de los videojuegos: El caso de World of Warcraft. Píxel-Bit. Revista de Medios y Educación, (48), 187-196. http://dx.doi.org/10.12795/pixelbit.2015.i48.12

Ramírez-Granizo, I. A., Ubago-Jiménez, J. L., González-Valero, G., Puertas-Molero, P., \& Román-Mata, S. (2020). The Effect of Physical Activity and the Use of Active Video Games: Exergames in Children and Adolescents: A Systematic Review. International Journal of Environmental Research and Public Health, 17(12), 4243. https://dx.doi.org/10.3390\%2Fijerph17124243

Ranalli, J., \& Ritzko, J. (2013). Assessing the Impact of Video Game Based Design Projects in a First Year Engineering Design Course. In IEEE Frontiers in Education Conference (FIE), 530-534.

https://pdfs.semanticscholar.org/f6a8/1665b1ed5663abffb67c7bb529b4ae9fc642.pdf

Rubio Méndez, M (2012). Retos y posibilidades de la introducción de videojuegos en el aula. Revista de Estudios de Juventud, (98), 2012, 118-134. http://www.injuve.es/sites/default/files/Revista98_9.pdf

Rugelj, J., \& Lapina, M. A. (2019). Game Design Based Learning of Programming. https://www.researchgate.net/publication/337199044_Game_Design_Based_Learning_of Programming 
Ruiz Falcó, M. L. (2018). Consejos y recomendaciones para el manejo de la epilepsia en niños. ESTEVE. Hospital Niño Jesús. http://archivosweb.esteve.com/pacientes/epilepsia/consejos-para-el-manejo-de-laepilepsia-en-ninos.pdf

Sánchez Guzmán, L. A., y Galvis Martínez, L. P. (2016). Fuera del aula: ambientes divertidos para un aprendizaje significativo (Trabajo de grado de pregrado). https://repository.uniminuto.edu/handle/10656/4777

Sánchez Peris, F. J., y Esnaola Horacek, G. A. (2014). Los videojuegos en la educación. Aularia: Revista Digital de Comunicación, 3(1), 21-26. http://rabida.uhu.es/dspace/bitstream/handle/10272/9259/Los_videojuegos.pdf?sequence $=2$

Short, D. (2012). Teaching Scientific Concepts using a Virtual World - Minecraft. Teaching Science, 58(3), 55-58. http://zonaminecraft.info/wp-content/uploads/2021/02/Short-2012science-teaching-minecraft.pdf

Soriani, A., Ilardo, M., \& Falconi A. (2018). Videogames, Violence and Aggressive Behavior: an Educational Proposal. Proceedings of Play2Learn, 11-30. http://gamilearning.ulusofona.pt/wp-content/uploads/full_P2L_Proceedings.pdf\#page=11

Soto-Ardila, L. M., Melo Niño, L., Caballero, A., y Luengo, R. (2019). Estudio de las opiniones de los futuros maestros sobre el uso de los videojuegos como recurso didáctico a través de un análisis cualitativo. Revista Ibérica de Sistemas e Tecnologias de Informação, (33), 4863. https://dx.doi.org/10.17013/risti.33.48-63

Squire, K., \& Jenkins, H. (2003). Harnessing the power of games in education. Vision, 3(1), 5-33. http://dx.doi.org/10.4236/ce.2013.47A1001

Suárez-Álvarez, R., y Vázquez-Barrio, T. (2019). La gamificación aplicada a la educación como recurso "learning by doing" y "learning by interacting" en alumnos de Educación Secundaria Obligatoria. En Redine (Ed.), Edunovatic 2019 conference proceedings: 4th Virtual International Conference on Education, Innovation and ICT (18-19) (pp. 91-94). Redine. http://www.edunovatic.org/wp-content/uploads/2020/03/EDUNOVATIC19.pdf 
Svensson, L. (2013). Semi-fictionalized History as Teaching Aids - Opportunities for learning history in Assassin's Creed II as a digital game and novel. Göteborgs universitet. https://130.241.16.4/bitstream/2077/34538/1/gupea_2077_34538_1.pdf

Swalwell, M. (2012). The Early Micro User: Games writing, hardware hacking, and the will to mod. Proceedings of DiGRA Nordic 2012 Conference: Local and Global Games in Culture and Society, $10, \quad 3-4 . \quad$ http://www.digra.org/wp-content/uploads/digitallibrary/12168.37411.pdf

Rivera Arteaga, E., y Torres Cosío, V. (2018). Videojuegos y habilidades del pensamiento / Videogames and thinking skills. RIDE, 8(16), 267-288. https://doi.org/10.23913/ride.v8i16.341

Tan, W. H., Neill, S., \& Johnston-Wilder, S. (2013). Deep Learning and the use of Spore ${ }^{\mathrm{TM}}$ in ALevel Biology Lessons. University of Warwick.

Tejedor, S., y Tusa Jumbo, F. E. (2020). Los newsgames como herramienta periodística: Estudio de caso de experiencias de éxito. Revista Prisma Social, (30), 115-140. https://revistaprismasocial.es/article/view/1543/4353

Vázquez Cano, E., y Ferrer Delgado E. (2015). La creación de videojuegos con Scratch en educación secundaria. Communication papers: media literacy and gender studies, 4(6), 63-73. https://core.ac.uk/download/pdf/39157622.pdf

Wainwright, A. M. (2014). Teaching Historical Theory through Video Games. The History Teacher, 47(4), 579-612. https://doi.org/10.1177\%2F1046878116646693

Wijman, T. (2019). The Global Games Market Will Generate \$152.1 Billion in 2019 as the U.S. Overtakes China as the Biggest Market. Newzoo. https://newzoo.com/insights/articles/theglobal-games-market-will-generate-152-1-billion-in-2019-as-the-u-s-overtakes-china-asthe-biggest-market/

Wu, B., \& Inge Wang, A. (2012). A Guideline for Game Development-Based Learning: A Literature Review. International Journal of Computer Games Technology, 1-20. https://doi.org/10.1155/2012/103710

Yepes Miranda, D. (2020). Stem y sus oportunidades en el ámbito educativo (Monografía de pregrado). 


\section{Percepciones de}

los estudiantes

Percepciones de los estudiantes | Revista Virtual Universidad Católica del Norte, 64, 5-40 ISSN: 0124-5821 (En línea)

https://repositorio.unicordoba.edu.co/bitstream/handle/ucordoba/2774/yepesmirandadeim er.pdf? sequence $=1$ \&isAllowed $=\mathrm{y}$ 


\section{Anexo I: Cuestionario sobre hábitos de consumo y videojuegos educativos}

Estimado estudiante, a continuación, te solicitamos que respondas con sinceridad a una serie de afirmaciones sobre tus hábitos de consumo de videojuegos, el uso que hacen los profesores de las nuevas tecnologías en sus clases y tus perspectivas sobre el diseño y desarrollo de videojuegos y los videojuegos educativos. Entendemos como Videojuego Educativo aquel que ha sido diseñado para que el jugador aprenda algo específico, más allá de su función como instrumento de ocio y entretenimiento.

Los datos que se obtengan serán tratados de forma confidencial, asegurando el anonimato de los participantes. Gracias por tu colaboración.

\section{A. DATOS IDENTIFICATIVOS}

1. Edad:

2. Curso:
a. Primero de la ESO
b. Segundo de la ESO
c. Tercero de la ESO
d. Cuarto de la ESO
e. Primero de Bachillerato
f. Segundo de Bachillerato

3. Sexo:
a. Masculino
b. Femenino

4. Indica aproximadamente el tiempo diario que juegas a videojuegos:
a) Menos de 1 hora diaria
b) En torno a 1 hora diaria
c) En torno a 2 horas diarias
d) En torno a 3 horas diarias o más

5. Indica aproximadamente el tiempo diario que juegas a videojuegos con propósitos educativos:
a. Menos de 1 hora diaria
b. En torno a 1 hora diaria
c. En torno a 2 horas diarias
d. En torno a 3 horas diarias o más

6. Por favor, en el caso de que juegues a videojuegos, indica a cuáles:

A continuación, se presentan una serie de afirmaciones relacionadas con la temática. Por favor, selecciona del 1-4 tu grado de acuerdo o desacuerdo, siendo 4: "totalmente de acuerdo" y el 1: "totalmente en desacuerdo".

\section{B. PROFESORES Y NUEVAS TECNOLOGÍAS}

Queremos saber si tus profesores utilizan las nuevas tecnologías en sus clases y si te gustaría que hicieran más uso de ellas

7. Mis profesores utilizan las nuevas tecnologías en sus clases 


\begin{tabular}{|l|c|l|l|l|}
\hline 8. & $\begin{array}{c}\text { Me gustaría que los profesores hicieran más uso de las nuevas } \\
\text { tecnologías en sus clases }\end{array}$ & & & \\
\hline 9. & Mis profesores utilizan videojuegos en sus clases & & & \\
\hline 10. & Me gustaría que los profesores utilizaran videojuegos en sus clases & & & \\
\hline 11. & $\begin{array}{c}\text { Me gustaría que los profesores desarrollaran sus propios materiales } \\
\text { educativos empleando las nuevas tecnologías }\end{array}$ & & \\
\hline
\end{tabular}

\begin{tabular}{|c|c|c|c|c|c|}
\hline & $\begin{array}{l}\text { MPACTO PEDAGÓGICO DE LOS VIDEOJUEGOS } \\
\text { edimos que reflexiones sobre qué te aportan los videojuegos y si tienen } \\
\text { n impacto sobre tu educación. }\end{array}$ & 1 & 2 & 3 & 4 \\
\hline 12. & Los videojuegos aumentan mi motivación & & & & \\
\hline 13. & $\begin{array}{l}\text { Los videojuegos mejoran mis habilidades en el manejo de la } \\
\text { información y las nuevas tecnologías }\end{array}$ & & & & \\
\hline 14. & Los videojuegos mejoran mi capacidad de aprendizaje & & & & \\
\hline 15. & Los videojuegos mejoran mi capacidad de comunicación & & & & \\
\hline 16. & Los videojuegos mejoran mi capacidad de colaboración & & & & \\
\hline 17. & Los videojuegos mejoran mi capacidad de resolución de problemas & & & & \\
\hline 18. & Los videojuegos me ayudan a desarrollar habilidades profesionales & & & & \\
\hline 19. & Los videojuegos me ayudan a desarrollar mi creatividad & & & & \\
\hline
\end{tabular}

\begin{tabular}{|l|l|l|l|l|}
\hline $\begin{array}{l}\text { D. PERSPECTIVAS SOBRE LOS VIDEOJUEGOS EDUCATIVOS } \\
\text { En este apartado te pedimos que te centres en esos videojuegos que han } \\
\text { intentado enseñarte algo y pienses si han conseguido su objetivo. }\end{array}$ & 1 & 2 & 3 & 4 \\
\hline 20. & Los videojuegos educativos son divertidos & & & \\
\hline 21. & Los videojuegos educativos son innovadores & & & \\
\hline 22. & Los videojuegos educativos me aportan nuevos conocimientos & & & \\
\hline 23 & Los videojuegos educativos mejoran mis habilidades & & \\
\hline 24. & Los videojuegos educativos son atractivos & & \\
\hline
\end{tabular}




\section{E. PERSPECTIVAS SOBRE EL DISEÑO Y DESARROLLO DE} VIDEOJUEGOS

Queremos saber si te interesan los videojuegos a nivel profesional, o si son un área de conocimiento que te interesa y te gustaría ampliar tus conocimientos al respecto.

26. Me gustaría dedicarme a una profesión relacionada con las STEAM (Ciencias, Tecnología, Ingeniería, Arte y Matemáticas)

27. Tengo interés por el diseño y desarrollo de videojuegos

28. He tenido experiencias previas en el diseño y desarrollo de videojuegos

29. Me gustaría dedicarme al diseño y desarrollo de videojuegos

30. Diseñar videojuegos sobre una materia aumentaría mi interés sobre la misma

31.

Me gustaría incorporar el diseño y desarrollo de videojuego durante las clases

32. Si lo deseas, puedes añadir cualquier otro comentario relacionado con la temática:

Muchas gracias por tu colaboración. 